\title{
Banking union in Europe: How much centralisation is needed?
}

\author{
Wolfram Berger* and Yoko Nagase $\dagger$
}

\begin{abstract}
We examine the efficiency of banking regulation in a federation with two tiers of government and highly integrated banking systems. We assume that policy makers have incomplete information about banks' true health, and banking sector turmoil can generate cross-border spill-over effects. We show that, in such an environment, the decentralisation of policy responsibilities for the regulation of banks can achieve the first-best allocation and ensure financial stability. While national governments design banking regulations, the federal policy maker authorises inter-regional income redistribution payments throughout the federation. Our results suggest that strengthening national responsibilities in banking regulation and supervision in the course of the further development of the European banking union may be advisable.
\end{abstract}

Keywords: banking union, banking regulation, decentralisation, inter-regional transfers, rotten kid theorem

JEL classification: G21, G28

\footnotetext{
* Corresponding author. Brandenburg University of Technology Cottbus, Department of Macroeconomics, Postbox 101344, 03013 Cottbus, Germany. Phone +49 35569 3969, email: bergerw@tu-cottbus.de.

$\uparrow$ Oxford Brookes University, Faculty of Business, Wheatley Campus, Oxford 0X33 1HX, United Kingdom. Phone +44 1865 485997, email: ynagase@ brookes.ac.uk.
} 


\section{Introduction}

Banking regulation, supervision and resolution have been subject to fundamental changes in the eurozone as part of European policymakers' response to the recent crisis. The crisis has laid bare the stability risks of ever-deepening financial integration supported by a common currency, and growing cross-border banking in combination with national responsibilities for banking policy. The notion that banking sectors in the eurozone have reached a level of integration that requires an integrated approach to their regulation has found widespread support.1 The purpose of the new institutional set-up that has emerged in the eurozone, and arguably constitutes more than the nucleus of a banking union, is to inter alia support a uniformly high standard of supervision, reduce national biases, help stem contagion, and prevent the building up of systemic risks in the banking sector, for example, by breaking the vicious cycle between sovereign debt and banking risks.2

Measures to complement the monetary union in Europe with a banking union were agreed upon and rapidly implemented. The authority of bank supervision was transferred from the national to the European level in November 2014 within the Single Supervisory Mechanism (SSM). The European Central Bank now is in charge of the supervision of the most significant banks in the eurozone and non-eurozone EU members, if they decide to join the SSM. Also in 2014, the Single Resolution Mechanism (SRM) was created. The purpose of the SRM is to ensure a timely and coordinated resolution or restructuring of failing banks in the eurozone, even though the resolution scheme is not yet fully operational, as an adequate resolution fund is yet to be built.

In all, the eurozone rapidly went from a decentralised to a centralised regime for banking policy. With this providing the context, the purposes of this paper are: first, to examine the efficiency of supra-national policy making in regulating the banking sector, especially in comparison to a decentralised policy regime. Second, we ask if the introduction of decentralised policy making elements into an otherwise federally governed policy area can be beneficial, in the presence of cross-border spill-over effects and informational asymmetry.

\footnotetext{
1 The case for a coordinated regulation of banks in Europe was already made by, e.g., Schoenmaker and Oosterloo (2005), and Vives (2001) well before the crisis. Allen et al. (2011) provide a report on the role of banks in cross-border finance in Europe up to and in the recent crisis, their role for financial stability and implications for macroeconomic policy. Taylor (2012) discusses the interdependencies between global banking, financial crises and real economic activity.

2 See, e.g., Goyal et al. (2013) for a review. Shambaugh (2012) views the crisis in the eurozone as the result of three interlocking crises: a banking crisis, a sovereign debt crisis and a growth crisis.
} 
More broadly, the paper also contributes to the debate on the efficiency of policy making with more than one tier of government.

This question of national versus supra-national bank supervision and regulation has been addressed from several perspectives in the literature. Beck, Todorov and Wagner (2013) point to banks' cross-border activities and argue that in their presence, regulatory interventions by national authorities are usually inefficient. If a large share of deposits and assets are held abroad, national regulators have an incentive to be too lenient in their regulatory decisions. 3 Holthausen and Ronde (2004) point to another source of inefficiency of national regulation. In their model, national supervisors, acting in the best interest of their own economies, do not completely reveal their information to their counterparts in other countries when they share responsibility for the regulation of multinational banks.

Dell'Arricia and Marquez (2006) model the decision between centralised and decentralised banking regulation as the outcome of the following trade-off. On one hand, national regulation may lead to sub-optimal regulation standards because the positive externalities that a stable banking sector generates for the neighbouring countries are not taken into account or because regulators wish to provide domestic banks with a competitive advantage over foreign banks. On the other hand, supra-national bank regulation comes at a cost-uniform standards have to be applied, i.e., flexibility in the design of customised solutions is lost. As these costs are higher for more asymmetric countries, the centralisation of banking regulation only pays off if the regulatory standards and needs of the participating countries are not too dissimilar. Morrison and White (2009) reach a similar conclusion but focus on a different trade-off. They argue that, if the skills and competences of national regulators vary across countries, a common regulation standard may be beneficial even if it means imposing the standard of the weakest member upon all economies. This is why giving up national regulatory authority is more likely to generate a welfare gain for countries with similar regulatory standards. Without a level playing field banks have an incentive to change locations and move across borders into economies with more competent regulators to benefit from, inter alia, higher depositor confidence and more adequate capital requirements. This will give rise to welfare losses because public confidence in banks that are not chartered by highly competent regulators will

\footnotetext{
3 Calzolari and Loranth (2011) examine a related question. They look at how the representation of a multinational bank abroad (subsidiary or branch) distorts the (national) regulator's intervention decisions, and analyse how this feeds back into a bank's decision to expand abroad and what form of representation to choose.
} 
suffer. Acharya (2003) cautions against a narrow understanding of regulatory policy coordination. If coordination does not pertain to all regulatory instruments, a detrimental welfare effect could emerge. A race to the bottom may result in initially more stringent regulators adopting a more lenient stance regarding non-coordinated regulation instruments.

We follow a different route and shed light on a previously unexplored issue. While the previous work, as briefly reviewed above, considers two economies and their incentives to cooperate in banking regulation, we model a federation of countries with more than one tier of government and examine which tier is best suited to control the stability of interconnected banking sectors. 4 In doing so, we consider that the different tiers of government in a federation pursue different policy objectives. This paper demonstrates that even if national policy makers are only concerned with domestic welfare, spill-over effects do not necessarily require a centralized approach to bank regulation if an income redistribution scheme between the countries is in place. We also show that national policy makers can implement the efficient allocation despite having incomplete information about the true stability of their banking sector. We illustrate our points with the help of a highly stylized model of a banking union.5

Our model considers a federation consisting of two countries and a supra-national policy maker. While the banking sector in one of the countries may be ailing, the other one is known to be structurally healthy. However, information is asymmetrically distributed. Only the banks in the first country possess private information about the true state of their balance sheets. We further assume that both banking sectors are interconnected. A banking crisis in one country will create negative spill-overs for the stability of the neighbouring country's banking sector. Two institutional solutions are compared. In the decentralised setting, bank regulation is decided at the national level, with regulation being modeled as affecting banks' lending costs. However, we assume that the supra-national policy maker can initiate inter-regional transfers after observing national policy decisions. In the centralised policy regime, the supra-national

\footnotetext{
4 Banking systems are modelled as representative banks in this paper. Regulatory challenges arising from the interplay of heterogeneous banks therefore are beyond the scope of our model. Saha and Sensarma (2010) present a model with heterogeneous banks that seems particularly relevant in the crisis context. They show that complex interactions may arise if (partially) nationalised banks and banks in full private ownership coexist. Their results suggest that, among other things, privately owned banks may react with more aggressive performance incentives for managers if other banks are transferred into public ownership. This may be welfareenhancing but also has the potential to be detrimental for financial stability if the regulation and supervision of the banking sector is flawed and, e.g., does not discourage excessive risk taking.

5 Our model is similar to that of Nagase and Silva (2000) who analyse the efficiency of a federation in controlling acid rain.
} 
regulator controls all policy instruments, i.e., the regulation of both national banking sectors is fully delegated to the supra-national level.

We show that the decentralised outcome corresponds to the centralised, constrained first-best allocation (i.e., the social planner's allocation constrained by information asymmetry). In the presence of inter-regional transfers between the member countries of the federation, even purely self-interested national governments efficiently control the health of their banking sectors, i.e., they act in the best interest of the whole federation by taking account of interregional spill-over effects. Put differently, spill-over effects and information asymmetries do not necessarily require transferring policy responsibilities to a higher tier of government. In an additional step, the model is extended to comprise a bank levy as an additional policy instrument controlled by national governments. We demonstrate that in such an environment, national governments are even able to implement the first-best allocation (i.e., the allocation a fully informed social planner would implement). Despite incomplete knowledge about the true health of their banking systems, national governments can implement a regulation policy customised to the risk accumulated in their banking systems.

From a theoretical perspective, our results are reminiscent of Becker's (1981) well-known Rotten Kid Theorem. The Rotten Kid Theorem demonstrates that in the presence of a benevolent parent, it may be in the best interest of selfish family members (kids) to maximise the overall (family) income instead of their individual incomes, even if their welfare depended only on their own consumption. From an economic policy perspective, our results do not reject the considerations outlined above, which led to the launch of the banking union. But they imply that strengthening decentralised responsibilities in its further development may be beneficial for the stability of the highly interconnected banking sectors in the eurozone.

The remainder of the paper is organised as follows. The theoretical set-up is presented in the following section. Sections 3 and 4 contain the analyses of the basic model in the centralised and decentralised policy regimes. In Section 5, we extend the model and introduce an additional policy instrument at the national level in order to improve upon the allocation derived from the basic version of the model in the previous sections. Section 6 concludes. 


\section{The model}

We consider a federation consisting of two countries, indexed by $i, i=1,2$. Both countries have their own national governments and banking systems. In order to focus on our main point, the efficiency of banking regulation in a federation with more than one tier of government, we assume that banks only operate within national borders.6 The banking system in country 1 can be in either a good or a bad state, possibly due to being unsustainably leveraged, while the banks' balance sheets in country 2 are known to be healthy. The fragility in the banking sector of country 1 can spill over to country 2 and threaten the stability of its banks too, for example due to exposures in the interbank lending market. There is also a supra-national policy maker at the federal (central) level, the Federal Policy maker (FP), who redistributes income between both the countries.

The sequence of events is as follows. In stage zero, the state of nature of the health of country 1's banking system is revealed. This information is assumed to be privately owned by the banks in country 1 . In stage 1, banking regulation policies are chosen. As policy makers possess only imperfect information about the health of country 1's banking system, their objective is to design incentive-compatible regulation policies that elicit information from the banking system regarding the true state of its balance sheets. If they are successful, a statedependent bank regulation can be implemented. After the policy plans have been drawn up, banks in both countries decide on their credit policies (stage 2). Finally, the policy maker on the federal level, after observing the banks' activities, decides on inter-regional income redistribution transfers between both countries (stage 3). Appendix 1 illustrates the basic setup of the model.

\subsection{Banking regulation, information sets and welfare}

The true state of banks' balance sheets in country 1 is private information of country 1 's banking sector. All policy makers, i.e., the governments of both countries and the supranational policy maker, as well as banks in country 2 only have incomplete information. To capture the assumed information asymmetry, we denote the state of the banking sector's

\footnotetext{
6 The entry of banks into foreign markets has been studied extensively in the literature. In a comprehensive empirical analysis based on a data set that comprises 795 individual banks in 39 countries covering the period 1999-2006, Lee, Hsieh and Dai (2012) find that foreign bank ownership typically leads to a decrease in both the profitability and overhead expenses of domestic banks. Their results also suggest that the positive effects of foreign bank entry are stronger in less developed countries.
} 
balance sheets in country 1 by $\delta$ and assume that only an ex-ante probability can be attached to two possible outcomes, healthy and unhealthy balance sheets. More specifically, we assume that from the policy makers' point of view, $\delta$ takes the value of either $\delta^{H}$, indicating that banks are over-leveraged, with probability $\gamma$; or of $\delta^{L}$, indicating healthy balance sheets with the corresponding probability $1-\gamma$. By assumption, $\delta^{H}>\delta^{L} . \delta^{H}$ indicates that the stability of the banking sector is at risk.

Banking regulation is captured through a single policy instrument, $r$, which can be understood as affecting the cost of lending activities, for example, through capital requirements. Hence, $r$ can be interpreted as a measure to de-leverage the representative bank. The policy setting in the state of nature $\delta=\delta^{j}$ is denoted by $r_{1}{ }^{j}$ so that the capital buffer's dependency on the riskiness of banks' balance sheets is captured.

Policy implementation is modelled as a contract between the policy maker and the banking sector. It is assumed that the banking sector is offered a policy contract whereby it is given the choice between different regulation requirements tailored to the possible states of nature $\delta^{j}$. In other words, banks must agree to accept either $r_{1}{ }^{H}$ or $r_{1}{ }^{L}$. The policy maker's goal in designing the policy contract is to induce banks to correctly self-declare the state of their balance sheets, thereby revealing their true type. In this case, the regulation policy is efficient because it is correctly tailored to the risk accumulated in the banking sector.

The expected welfare function for country 1 reads

$$
W_{1}=\gamma U\left(w_{1}^{H}\right)+(1-\gamma) U\left(w_{1}^{L}\right)
$$

where $U$ is a concave function and $w_{1}{ }^{j}$ expresses the ex-post "wealth" level in the state of nature $j$

$$
w_{1}^{j}=m_{1}+u\left(q_{1}^{j}\left(r_{1}^{j}\right)\right)+\tau_{1}^{j}-\frac{\delta^{j}}{2} q_{1}^{j}\left(r_{1}^{j}\right)^{2}-D\left(c_{1}^{j}\left(q_{1}^{j}\left(r_{1}^{j}\right)\right)\right), j \equiv H \text { or } L .
$$

$u$ is a concave function. $q_{1}{ }^{j}$ is country 1 's credit volume as a function of $r_{1}{ }^{j}$, while $\tau_{1}{ }^{j}$ denotes the inter-regional transfer payments to be authorised by the FP in stage 3, in the state of nature j. $m$ represents the economy's endowment and $\delta^{j} q_{1}{ }^{j}\left(r_{1}{ }^{j}\right)^{2} / 2$ describes the costs banks incur 
when lending $q_{1}^{j}$ units of credit. $D\left(c_{1}{ }^{j}\right)$ is the increasing and strictly convex social cost function related to country 1's credit volume, which in turn depends on the policy strategy chosen by the government $\left(c_{i}{ }^{j}\right.$ are detailed below $) .7$

Owing to the cross-border nature of banking and the international interconnectedness of banks, turmoil in the banking system of one country will not stop at national borders, but spill over to other countries. This particularly applies to monetary unions where a common currency spurs the development of deeper financial and banking links. We capture this aspect by assuming that balance sheet fragility in country 1 can spill over to the banking system in country 2, and thus trigger financial and banking sector problems there too. More specifically, the spill-overs are linked to the credit volume and the stability parameter $\delta^{j}$. The economic costs of bank lending can then be specified as

$$
\begin{aligned}
& c_{1}^{j}=\eta \delta^{j} q_{1}^{j} \\
& c_{2}^{j}=(1-\eta) \delta^{j} q_{1}^{j}+\delta^{L} q_{2}
\end{aligned}
$$

where $\eta$ is a spill-over parameter with $0<\eta<1$ and $j=H$ or $L$. The term $\delta^{L} q_{2}$ in equation (3b) indicates that there is no uncertainty regarding bank balance sheets in country 2 . These are known to be healthy.

Optimal banking regulation must fulfil individual rationality (IR) and, for country 1, incentive compatibility (IC) constraints for the banking system. Policy makers aim at inducing banks in country 1 to reveal their true type when choosing the banking regulation policy. The optimal regulation must therefore be designed such that banks are not worse off with the banking regulation tailored to their true type, rather than accepting the regulation policy designed for the other type. If this condition is met, a misrepresentation of their type does not pay and the regulation is incentive-compatible. Furthermore, the optimal regulation policy must not compromise banks' solvency, i.e., banks' profits must be non-negative after the regulation policy is implemented. For country 1 , these conditions can be captured formally as

$$
\mathrm{IR}_{L}: \quad \Pi_{1}\left(r_{1}^{L} ; \delta^{L}\right) \equiv\left(p_{1}-r_{1}^{L}\right) q_{1}^{L}-\frac{\delta^{L}}{2}\left(q_{1}^{L}\right)^{2} \geq 0
$$

\footnotetext{
7 Schularick and Taylor (2012) show that credit booms are an important predictor for future financial crisis.
} 


$$
\begin{array}{ll}
\mathrm{IR}_{H}: & \Pi_{1}\left(r_{1}{ }^{H} ; \delta^{H}\right) \equiv\left(p_{1}-r_{1}^{H}\right) q_{1}^{H}-\frac{\delta^{H}}{2}\left(q_{1}^{H}\right)^{2} \geq 0 \\
\mathrm{IC}_{L}: & \Pi_{1}\left(r_{1}{ }^{L} ; \delta^{L}\right) \geq \Pi\left(r_{1}{ }^{H} ; \delta^{L}\right) \\
\mathrm{IC}_{H}: & \Pi_{1}\left(r_{1}{ }^{H} ; \delta^{H}\right) \geq \Pi\left(r_{1}{ }^{L} ; \delta^{H}\right)
\end{array}
$$

where $\Pi_{1}\left(r_{1}^{j} ; \delta^{j}\right)$ with $j=H$ or $L$ denotes the profit function. The IR constraints in (4a) and (4b) ensure that it is individually rational for banks to accept the regulation and stay in the domestic market, while equations (5a) and (5b) constitute the IC constraints.

In country $2, r_{2}$ is used to maximise

$$
W_{2}=\gamma U\left(w_{2}{ }^{H}\right)+(1-\gamma) U\left(w_{2}{ }^{L}\right)
$$

with

$$
w_{2}^{j}=m_{2}+u\left(q_{2}\left(r_{2}\right)\right)+\tau_{2}^{j}-{\frac{\delta^{L}}{2}} q_{2}\left(r_{2}\right)^{2}-D\left(c_{2}{ }^{j}\left(q_{1}^{j}\left(r_{1}^{j}\right), q_{2}\left(r_{2}\right)\right)\right)
$$

where $j=H$ or $L$ denotes healthy $(L)$ or unhealthy $(H)$ balance sheets in country 1 , corresponding to the state of nature as indicated by $\delta^{j}$. In contrast to country 1 , there is no uncertainty about the ex-ante health of the banking sector in country 2. Yet, the policy maker has to take the possibility of negative spill-over effects stemming from a weak banking sector in country 1 into account when deciding on the optimal policy.

\subsection{Banks}

After the banking regulation has been decided, banks choose their optimal credit volumes (stage 2). A representative bank in country 1 maximises

$$
\Pi_{1}=\left(p_{1}-r_{1}^{j}\right) q_{1}^{j}-\frac{\delta^{j}}{2}\left(q_{1}^{j}\right)^{2}
$$

where $p_{1}$ denotes the revenue per credit unit lent and can be understood as reflecting the interest rate banks charge. $p_{1}$ is assumed to be determined by the credit market, and is 
exogenous for the bank. By assumption, $p_{1}>r_{1}{ }^{j}$. A representative bank in country 2 maximises

$$
\Pi_{2}=\left(p_{2}-r_{2}\right) q_{2}-\frac{\delta^{L}}{2}\left(q_{2}\right)^{2}
$$

with $p_{2}>r_{2}$.

\subsection{Federal policy maker}

The federal policy maker's role in our model is to balance out income disparities between the two countries by initiating inter-regional income redistribution payments. Income will be redistributed from the "rich" to the "poor" country, as measured by $w_{i}{ }^{j}$. The extent of income redistribution through the federal policy maker is determined not only by the state of nature of country 1's banking sector, banking regulation, and credit volumes in both countries, but also by the strength of possible cross-country spill-over effects in the banking sectors, represented by $\eta$. We assume that the federal policy maker faces the same informational constraints as national policy makers. 8

After observing the activities of banks in both countries, the risk-neutral FP, who is equally concerned about welfare in both countries, chooses inter-regional transfer payments $\left\{\tau_{1}{ }^{j}, \tau_{2}{ }^{j}\right\}$, $\tau_{1}^{j}+\tau_{2}^{j}=0$ to maximise her objective function in stage 3 :

$$
W^{j}=U\left(w_{1}^{j}\right)+U\left(w_{2}^{j}\right), \quad j=H \text { or } L
$$

\section{Centralised banking regulation}

In the next two sections, we will derive and study the model solution, assuming two different institutional set-ups for policy-making. We first suppose that the FP controls all policy instruments, i.e., sets both $\tau_{i}{ }^{j}$ and $r_{i}{ }^{j}$ so that there is no role for the national governments in policy making. In this scenario, the responsibility for banking regulation fully lies with the supra-national policy maker, and we will therefore refer to it as the centralised solution. The resulting allocation constitutes the constrained (i.e., subject to distortions caused by information asymmetry) social optimum. Decentralisation is the second policy-making

8 Beck, Todorov and Wagner (2013) suggest that a supra-national regulator might even have an informational disadvantage. 
scenario we consider. It differs from the first only in that the governments of countries 1 and 2 are now in charge of the banking regulation in their economies. The FP retains the interregional transfer payments as her policy instrument in stage 3 of the game. We will study and compare the subgame perfect equilibria for the game in both policy regimes. In doing so, we will focus on the policy game in country 1 and omit equations for country 2 wherever possible.

The model is solved by backward induction. As $\tau_{2}^{j}=1-\tau_{1}^{j}$, it is obvious that it is optimal for the FP to achieve

$$
w_{1}^{j}=w_{2}^{j} \equiv w^{j}, \quad j=H \text { or } L .
$$

in stage 3 of the game. Solving (10) for $\tau_{1}^{j}$ shows that the optimal inter-regional transfer payment can be expressed as a function of stage 2 choice variables:

$$
\tau_{1}^{j}=\tau_{1}^{j}\left(q_{1}^{j}, q_{2}\right), \quad j=H \text { or } L
$$

In stage 2 , banks maximise their profit functions as given in (8a) and (8b), respectively, taken the regulation policy as represented by $r_{1}^{j}$ as given. Profit maximisation occurs after policy makers have implemented the optimal regulation policy or, in the theoretical terms of our model, banks in country 1 have accepted a regulation contract $r_{I}^{j}$ and thus provided information about their type.

The usual condition of profit and cost equalisation at the margin, $\left(p_{1}-r_{1}{ }^{j}\right)=\delta^{j} q_{1}{ }^{j}$, can be more conveniently rewritten as

$$
\begin{gathered}
q_{1}^{j}\left(r_{1}^{j}, \delta^{j}, p_{1}\right)=\frac{p_{1}-r_{1}^{j}}{\delta^{j}} \\
q_{2}\left(r_{2}\right)=\frac{p_{2}-r_{2}}{\delta^{L}}
\end{gathered}
$$

for $j=H$ or $L$. Substituting (12a) and (12b) into (8a) and (8b) yields the indirect profit functions for both banking sectors 


$$
\begin{aligned}
& \Pi_{1}\left(r_{1}{ }^{j}, \delta^{j}, p_{1}\right)= \\
& \Pi_{2}\left(r_{2} ; \delta^{L}, p_{2}\right)=\frac{\left(p_{1}-r_{1}^{j}\right)^{2}}{2 \delta^{j}} \\
& 2 \delta^{L}
\end{aligned}
$$

for $j=H$ or $L$. We require that $p_{1} \geq r_{1}$ (and $p_{2} \geq r_{2}$ ), i.e., banks are assumed to make a nonnegative profit in all states of nature. Hence, the IR constraints (4a) and (4b) are automatically fulfilled.

In the centralised regime, decisions about banking regulation, i.e., the setting of the policy instruments $r_{i}$ are made at the federal level. All policy responsibilities regarding the banking sectors are transferred from the national governments to the supra-national policy maker. In stage 1 of the game, the FP will therefore set $\left\{r_{1}{ }^{j}, r_{2}\right\}, j=H$ or $L$, to maximise a weighted average of welfare in the two possible states of nature

$$
V=\gamma W^{H}+(1-\gamma) W^{L}
$$

subject to equations (2), (3a), (3b), (5a), (5b), (7), (10), (11), (12a), and (12b). Using the indirect profit functions (13a) and (13b), the incentive compatibility constraints $\mathrm{IC}_{L}$ and $\mathrm{IC}_{H}$ in equations (5a) and (5b) can be expressed as

$$
\begin{aligned}
& \frac{\left(p_{1}-r_{1}^{L}\right)^{2}}{2 \delta^{L}} \geq \frac{\left(p_{1}-r_{1}^{H}\right)^{2}}{2 \delta^{L}}, \\
& \frac{\left(p_{1}-r_{1}^{H}\right)^{2}}{2 \delta^{H}} \geq \frac{\left(p_{1}-r_{1}^{L}\right)^{2}}{2 \delta^{H}} .
\end{aligned}
$$

It is straightforward to see that (15a) and (15b) lead to the following proposition.

Proposition 1. The centralised outcome results in a pooling outcome, i.e., $r_{1}{ }^{H}=r_{1}{ }^{L} \equiv r_{1}$. Both IC constraints are binding.

The rationale behind Proposition 1 is that given their profit functions, banks are not induced to reveal their type. In this version of our model, banking regulation cannot be tailored to the 
needs of the banking sector. Policy makers lack the information required to effectively enforce a type-dependent regulation policy.9 This means that, even if needed, the government of country 1 does not implement a tighter banking regulation because it only has incomplete information about the health of banks' balance sheets and policy makers cannot accurately deduce their type. However, in combination with (12a) and (12b), Proposition 1 directly yields the following corollary:

Corollary: The centralised outcome results in $q_{1}{ }^{L} \geq q_{1}^{H}$.

Even though the policy instrument is not tailored to the two types, observation of the resulting output level in stage 2 will reveal the actual type. If we further consider that $\delta^{L}<\delta^{H}$, the indirect profit function (13a) in conjunction with Proposition 1 yields

$$
\Pi_{1}\left(r_{1} ; \delta^{L}, p_{1}\right)-\Pi_{1}\left(r_{1} ; \delta^{H}, p_{1}\right)=\frac{\left(p_{1}-r_{1}\right)^{2}}{2 \delta^{L}}-\frac{\left(p_{1}-r_{1}\right)^{2}}{2 \delta^{H}}>0 .
$$

This leads to a second result.

Proposition 2. The centralised outcome results is

$$
\Pi_{1}\left(r_{1} ; \delta^{L}, p_{1}\right)>\Pi_{1}\left(r_{1} ; \delta^{H}, p_{1}\right)
$$

The optimal policy mix implies that banks make higher profits in state of nature $j=L$, i.e., if their balance sheets are healthy.

To finalise the characterisation of the constrained social optimum, the conditions that the values of the policy variables, $r_{1}$ and $r_{2}$, have to fulfil in equilibrium need to be determined. To do that, we use (2), (3a), (3b), (7), and (11) to express the central policy maker's objective function (14) as

$$
W\left(r_{1}, r_{2}\right)=2 \gamma U\left(w^{H}\left(r_{1}, r_{2}\right)\right)+2(1-\gamma) U\left(w^{L}\left(r_{1}, r_{2}\right)\right)
$$

\footnotetext{
${ }_{9} \mathrm{We}$ will come back to this point in section 4 where we will show that the introduction of an additional policy instrument leads to a separating equilibrium.
} 
The derivation of $w^{j}\left(r_{1}, r_{2}\right), j=H$ or $L$ is given in the Appendix 2. $r_{1}$ and $r_{2}$ must fulfil the following set of first-order conditions:

$$
\begin{aligned}
& \gamma U^{\prime}\left(w^{H}\right)\left[u^{\prime}\left(q_{1}^{H}\right)-\left(p_{1}-r_{1}\right)-\eta \delta^{H} D^{\prime}\left(\eta q_{1}^{H}\right)-(1-\eta) \delta^{H} D^{\prime}\left((1-\eta) \delta^{H} q_{1}^{H}+\delta^{L} q_{2}\right)\right] \\
& +(1-\gamma) U^{\prime}\left(w^{L}\right)\left[u^{\prime}\left(q_{1}^{L}\right)-\left(p_{1}-r_{1}\right)-\eta \delta^{L} D^{\prime}\left(\eta \delta^{L} q_{1}^{L}\right)-(1-\eta) \delta^{L} D^{\prime}\left((1-\eta) \delta^{L} q_{1}^{L}+\delta^{L} q_{2}\right)\right] \\
& =0 \text {. } \\
& \gamma U^{\prime}\left(w^{H}\right)\left[u^{\prime}\left(q_{2}\right)-\left(p_{2}-r_{2}\right)-\delta^{L} D^{\prime}\left((1-\eta) \delta^{H} q_{1}^{H}+\delta^{L} q_{2}\right)\right] \\
& +(1-\gamma) U^{\prime}\left(w^{L}\right)\left[u^{\prime}\left(q_{2}\right)-\left(p_{2}-r_{2}\right)-\delta^{L} D^{\prime}\left((1-\eta) \delta^{L} q_{1}^{L}+\delta^{L} q_{2}\right)\right]=0
\end{aligned}
$$

\section{Decentralised solution}

As pointed out above, in the decentralised policy regime, each national government is in charge of setting its own banking regulation instrument $r$, whereas the power of the FP is confined to initiating the inter-regional transfer payment $\tau_{1}=-\tau_{2}$. Therefore, stages 2 and 3 of this game are identical to those of the centralised game. In stage 1, the governments of both countries simultaneously decide on the optimal regulation of their banking sectors. The government of country 1 maximises the national expected welfare function $W_{1}$ as expressed by (1), subject to (2), (3a), (3b), (5a), (5b), (7), (10), (11), (12a), and (12b). Similarly, the government of country 2 maximises expected national welfare $W_{2}$ as expressed by (6), subject to (2), (3a), (3b), (7), (10), (11), (12a), and (12b). As in the case of the centralised policy game, the only feasible incentive-compatible mechanism is the one that yields pooling. In other words, Proposition 1 continues to hold, and hence we have $r_{1}{ }^{H}=r_{1}{ }^{L} \equiv r_{1}$ in the decentralised policy game as well. Our result for decentralised policy-making can be summarised as follows:

Proposition 3. The decentralised equilibrium is identical to that of the centralised outcome, as defined by (18a) and (18b). The subgame perfect equilibrium for the decentralised policy regime implements the constrained social optimum. 
The important policy implication of Proposition 3 is that despite the spill-overs, national banking policies can still be efficient. The existence of spill-over or "contagion" effects alone may not be sufficient reason to defer the responsibility for banking regulation to a supranational level. The essence of Proposition 3 is that the income transfers initiated by the supranational policy maker change the incentives of the national governments and align them with those of the supra-national policy maker. Even in the decentralised policy regime, maximising the sum of national wealth levels, i.e., adopting a "European" perspective, is the optimal policy objective for national policy makers. This result is reminiscent of the well-known Rotten Kid Theorem introduced by Becker (1981), albeit in a different context. The Rotten Kid Theorem stipulates that even purely self-interested family members ("rotten kids") can be induced to act in the common (family) interest, if a "benevolent parent" distributes income between them.10 This result implies that the ability of national banking policies to promote union-wide objectives has been underestimated in the debate so far. In his critique of the European banking union, Tröger (2014) criticises the excessive confidence in the centralisation of banking regulation in the EU and points out that centralisation is not an argument in itself. Centralisation is only called for if the alternatives are less effective. He identifies an imbalance between the ECB as the (now) leading supra-national authority in banking regulation in the eurozone and national authorities that remain involved in bank supervision and questions the effectiveness of an institutional set-up that provides the supranational institution with a dominant role while requiring close cooperation with national bodies.11

Our model suggests that the risk of coordination failures that may occur if financial and banking markets are interconnected but banking regulation remains with national authorities have been overstated in the recent debate. These coordination failures are at the heart of the argument in favour of a banking union in Europe and have led Schoenmaker $(2011,2013)$ to postulate a financial trilemma. The financial trilemma stipulates that only two of the three objectives, namely financial stability, interconnected banking sectors and national financial

\footnotetext{
10 Originating in household and family economics the Rotten Kid Theorem has been applied to various other contexts, including the cost-effective resolution for agency problems in firms (Chami and Fullenkamp, 2002), the allocation of policy autonomy to the different tiers of government in a federation (Caplan, Cornes and Silva, 2000 and Silva, 2016), intergenerational transfers (Jürges, 2000), environmental policy (Nagase and Silva, 2000) and evolutionary biology (Bergstrom and Bergstrom, 1999).

11 Another conflict that may arise in the centralised regime is that between supervision and monetary policy, which is also pointed out by proponents of the banking union in the eurozone such as Pisani-Ferry et al. (2012). The notion of potential trade-offs between monetary and financial stability may be hard to dispel with the ECB assuming the role of the key player in bank supervision.
} 
policies, can be achieved simultaneously. The reason is that national authorities make decisions from their own purely national perspectives, thereby potentially jeopardizing stability on integrated financial markets. However, the inadequacy of national banking policies in the eurozone may be over-emphasised. Purely national decision making and acting in the best interest of the home country can lead to the optimal outcome on the supra-national level if policy instruments are correctly designed.

\section{$5 \quad$ Model extension: introducing a national bank levy}

Neither the centralised nor the decentralised policy regime is able to implement the first-best allocation. Even though both can deliver the constrained first-best, the problem of information asymmetry cannot be overcome. Now imagine the inter-regional income distribution transfers are complemented by intra-regional payments between the national governments and their banking systems, implemented for example in the form of a bank levy. In other words, an element of decentralised policy-making is introduced. In integrating such a policy instrument into our model, we start from the centralised policy regime as discussed in section 3 in order to capture (aspects of) policy making in the European Monetary Union. Therefore, it is assumed again that, next to the inter-regional transfers, the FP also controls the banking regulation in the federation.12

Such payments enter the welfare function of the two countries, so that equations (2) and (7) are now expressed as

$$
\begin{gathered}
w_{1}^{j}=m_{1}+u\left(q_{1}^{j}\left(r_{1}^{j}\right)\right)+\tau_{1}^{j}-\frac{\delta^{j}}{2} q_{1}^{j}\left(r_{1}^{j}\right)^{2}-D\left(c_{1}^{j}\right)-x_{1}^{j} ; \quad j \equiv H \text { or } L \\
w_{2}^{j}=m_{2}+u\left(q_{2}\left(r_{2}\right)\right)+\tau_{2}^{j}-\frac{\delta^{L}}{2} q_{2}\left(r_{2}\right)^{2}-D\left(c_{2}^{j}\right)-x_{2}
\end{gathered}
$$

where $x_{i}$ denotes the transfer of resources between the banking system and government $i$.

Banks' profit functions now read

\footnotetext{
12 Since the centralised solution of chapter 3 and the decentralised solution of chapter 4 are identical as proved above, the government level on which $r$ and $\tau$ are set actually is inconsequential for the mathematical result in this section.
} 


$$
\begin{aligned}
& \Pi_{1}=\left(p_{1}-r_{1}^{j}\right) q_{1}^{j}-\frac{\delta^{j}}{2}\left(q_{1}^{j}\right)^{2}+x_{1}^{j} \\
& \Pi_{2}=\left(p_{2}-r_{2}\right) q_{2}-\frac{\delta^{L}}{2}\left(q_{2}\right)^{2}+x_{2}
\end{aligned}
$$

for $j=H$ or $L$; With $x_{i}$ in place, the IR and IC constraints become

$$
\begin{array}{ll}
\mathrm{IR}_{L}: \quad \Pi\left(r_{1}{ }^{L}, x_{1}{ }^{L} ; \delta^{L}\right) \equiv\left(p_{1}-r_{1}^{L}\right) q_{1}^{L}-\frac{\delta^{L}}{2}\left(q_{1}^{L}\right)^{2}+x_{1}{ }^{L} \geq 0 \\
\mathrm{IR}_{H}: \quad \Pi\left(r_{1}{ }^{H}, x_{1}{ }^{H} ; \delta^{H}\right) \equiv\left(p_{1}-r_{1}^{H}\right) q_{1}^{H}-\frac{\delta^{H}}{2}\left(q_{1}^{H}\right)^{2}+x_{1}{ }^{H} \geq 0 \\
\mathrm{IC}_{L}: \quad \Pi\left(r_{1}{ }^{L}, x_{1}{ }^{L} ; \delta^{L}\right) \geq \Pi\left(r_{1}{ }^{H}, x_{1}{ }^{H} ; \delta^{L}\right) \\
\mathrm{IC}_{H}: \quad \Pi\left(r_{1}{ }^{H}, x_{l}{ }^{H} ; \delta^{H}\right) \geq \Pi\left(r_{1}{ }^{L}, x_{1}{ }^{L} ; \delta^{H}\right)
\end{array}
$$

The modified model is solved by following the same steps as above. Using (4c), (4d), (5c), and (5d) yields the new incentive compatibility constraints for both states of nature as given in $(15 \mathrm{c})$ and $(15 \mathrm{~d})$

$$
\begin{aligned}
& \frac{\left(p_{1}-r_{1}^{L}\right)^{2}}{2 \delta^{L}}+x_{1}^{L} \geq \frac{\left(p_{1}-r_{1}^{H}\right)^{2}}{2 \delta^{L}}+x_{1}^{H} \\
& \frac{\left(p_{1}-r_{1}^{H}\right)^{2}}{2 \delta^{H}}+x_{1}^{H} \geq \frac{\left(p_{1}-r_{1}^{L}\right)^{2}}{2 \delta^{H}}+x_{1}^{L}
\end{aligned}
$$

(15c) and (15d) imply a fundamental change to Proposition 1. Proposition 1 is now replaced by (see Appendix 3 for the derivation):

Proposition 1!. Introducing a bank levy (national transfers) into the centralised outcome from section 3 results in $r_{1}{ }^{H} \geq r_{1}{ }^{L}$.

Corollary 1 and Proposition 2 continue to hold. The fundamental difference between Proposition 1 and Proposition 1' is that the latter describes a separating equilibrium (if it 
holds with strong inequality). Equations (15c) and (15d) show that banks will now reveal their type in both states of nature because the state-dependent levy $x_{1}^{j}$ introduces an incentive for banks to be truthful about their own type. In other words, the introduction of national transfers enables policy makers to customise banking regulations to the true health of their banking systems.

In order to determine the optimal values for $x_{1}{ }^{H}$ and $x_{1}{ }^{L}$ (2a), (3a), (3b), (7a), (11), (12a) and (12b) are substituted into the objective function (14) to obtain the Lagrangian equation (19) (the derivation of $w^{j}\left(r_{1}{ }^{j}, x_{1}{ }^{j}, r_{2}, x_{2}\right) ; j=H$ or $L$ is given in Appendix 4).

$$
\begin{aligned}
L\left(r_{1}{ }^{j}, x_{1}{ }^{j}, r_{2}, x_{2}\right) & =2 \gamma U\left(w^{H}\left(r_{1}{ }^{H}, x_{1}{ }^{H}, r_{2}, x_{2}\right)\right)+2(1-\gamma) U\left(w^{L}\left(r_{1}{ }^{L}, x_{1}{ }^{L}, r_{2}, x_{2}\right)\right. \\
+ & \mu^{H} \Pi\left(r_{1}{ }^{H}, x_{1}{ }^{H} ; \delta^{H}\right)+\mu^{L} \Pi\left(r_{1}{ }^{L}, x_{1}{ }^{L} ; \delta^{L}\right) \\
+ & \lambda^{H}\left[\Pi\left(r_{1}^{H}, x_{1}^{H} ; \delta^{H}\right)-\Pi\left(r_{1}^{L}, x_{1}^{L} ; \delta^{H}\right)\right] \\
+ & \lambda^{L}\left[\Pi\left(r_{1}^{L}, x_{1}^{L} ; \delta^{L}\right)-\Pi\left(r_{1}^{H}, x_{1}^{H} ; \delta^{L}\right)\right] .
\end{aligned}
$$

The first-order conditions with respect to $x_{1}{ }^{H}$ and $x_{1}{ }^{L}$ read

$$
\begin{aligned}
& \mu^{H}+\lambda^{H}-\lambda^{L}=0, \\
& \mu^{L}+\lambda^{L}-\lambda^{H}=0
\end{aligned}
$$

and imply $\mu^{H}=\mu^{L}=0$ as the Langrangian multipliers must be non-negative. It follows that the IR constraints do not bind for either case, i.e., $\Pi_{1}\left(r_{1}{ }^{L}, x_{1}{ }^{L} ; \delta^{L}\right)>0$ and $\Pi_{1}\left(r_{1}{ }^{H}, x_{1}{ }^{H} ; \delta^{H}\right)>$ 0 .

(20a) and (20b) also imply that $\lambda^{L}=\lambda^{H}$, with $\lambda^{L}, \lambda^{H} \geq 0$. The range of possible values for $\lambda^{L}$ and $\lambda^{H}$ can be further analysed with the help of the IC constraints given in equations (15c) and (15d). Both constraints cannot bind simultaneously as shown in Appendix 3. Hence, $\lambda^{L}$ and $\lambda^{H}$ must be zero, and the IC constraints, which stipulate that any type is not worse off with the contract tailored to her own type than the contract tailored to the other one, will not be binding at the optimum. This leads to another key result of our model. The informational distortions that policy makers face can be overcome and the resulting allocation corresponds to the first-best outcome, i.e., the outcome that would emerge in the absence of any informational asymmetry (see the derivation in Appendix 5): 


$$
\begin{gathered}
u^{\prime}\left(q_{1}^{j}\right)=p-r_{1}^{j}+\eta \delta^{j} D^{\prime}\left(c_{1}^{j}\right)+(1-\eta) \delta^{j} D^{\prime}\left(c_{2}^{j}\right) \\
u^{\prime}\left(q_{2}\right)=p-r_{2}+\delta^{L} D^{\prime}\left(c_{2}^{j}\right)
\end{gathered}
$$

Together, they yield $\left\{r_{1}^{j *}, r_{2}{ }^{*}\right\}$, and hence $\left\{q_{1}{ }^{j *}, q_{2}{ }^{*}\right\}$. The values of $x_{1}{ }^{H}$ and $x_{1}{ }^{L}$ must satisfy (A3) in Appendix 3, given $\left\{r_{1}^{H *}, r_{1}{ }^{L *}\right\}$. From Proposition 1' it then follows that the condition $x_{1}^{H *}>x_{1}{ }^{L *}$ must hold. Note that the sign of $x_{1}{ }^{H *}$ and $x_{1}{ }^{L *}$ is not pre-determined as long as profits remain non-negative (IR conditions), i.e., $x_{1}{ }^{H *}$ and $x_{1}{ }^{L *}$ can take the form of a levy, if negative, or a subsidy, if positive, for the banking system. Yet, in our model, a bank levy should not be understood as a penalty payment for endangering financial and economic stability. Instead, $x_{1}{ }^{H *}$ and $x_{1}{ }^{L *}$ provide policy makers with a lever to influence banks' profit maximisation in such a way that the information asymmetry between banks and policy makers is eliminated. This explains why, maybe somewhat counterintuitively at first, unhealthy balance sheets are associated with a higher subsidy or a lower levy, respectively, as compared to low risk banking, which makes the implementation of such an instrument politically challenging.

A bank levy has been introduced, e.g., in the UK, during the global financial crisis and, in the form of a "Financial Stability Contribution" for the financial sector, proposed by the IMF to the G-20 (IMF 2010). In both cases, a dual objective is pursued. Taxation is applied as a corrective tool to discourage overly risky behaviour but it is also meant to raise fiscal revenue and thereby contribute to funding future government intervention in the banking sector. The bank levy in the eurozone, introduced in 2015, is another example for a bank levy. Its purpose is to raise money for the Single Resolution Fund, a core element of the single resolution mechanism (SRM). The levy is based on the bank's size and its risk profile.13 The purpose of the bank levy in our model is to reveal risky behaviour; in this sense, it is not a corrective policy tool. The objective instead is to overcome the problem of information asymmetry between the regulator and the regulated institutions, which appears particularly pervasive in the banking sector. Against this backdrop, the bank levy in our model can be interpreted as being part of the supervision toolkit. Yet, it also links supervision with the resolution of banks. An implication of the (self-)revelation of the health of their balance sheets is that ailing banks benefit from a lower levy (or receive higher financial support, respectively) than

13 For a more comprehensive discussion of the purposes, design and implementation problems of taxation of the financial sector see Keen (2011). 
financially stable banks. This can be understood as a step towards dovetailing bank supervision and resolution. Many observers have pointed out that the introduction of common (centralised) supervision and centralised resolution procedures need to go hand in hand. Otherwise, coordination problems may arise, giving rise to less rather than more stability in banking sectors (Goyal et al., 2013 and Sapir, Hellwig and Pagano, 2012).

The conclusion is that information distortions as studied in this paper may not be an impediment for efficient decentralised policy-making. Given a well-defined set of policy instruments at their disposal and an income-redistribution scheme on the supra-national level, national governments may be in the position to control the stability of banking systems as efficiently as a social planer, despite cross-border spill-over effects and informational asymmetries. Hence, our results suggest that the introduction of further decentralised elements of policy-making should not be ruled out in the future development of the banking union in the eurozone. As pointed out above, our model thus provides a counterargument to the widespread notion that national banking regulation and interconnected banking sectors lead to coordination failures and cannot secure financial stability.14

\section{Conclusion}

The centralisation of banking regulation, supervision and resolution on the European level have been key issues of concern and consideration in the wake of the global financial crisis and its spill-over effects in the eurozone. In light of the recent institutional developments towards a banking union in the eurozone, we ask how much centralisation in banking policy is truly necessary to achieve the desired outcome, i.e., stability in closely interconnected banking sectors. We compare the efficiency of centralised and decentralised policy making in a model that incorporates asymmetric information and cross-border spill-over effects. Unlike other papers that deal with the question of cross-country cooperation in banking regulation, we analyse this issue in the model of a federation to capture elements of the European context. In our set-up, centralised policy-making is not superior to national banking regulation even though national governments are assumed to be selfish.

\footnotetext{
14 More generally, our model strengthens the case for decentralised leadership in federations such as the EU where self-interested regional governments and a central government interact, regional governments have (some) policy autonomy and interregional income transfers exist.
} 
We show that national governments can implement an efficient regulation of their banking sectors and ensure financial stability in our model. This means that, firstly, purely selfinterested national governments are induced to take inter-regional spill-over effects into account. The reason is that the policy maker on the federal level redistributes income between both countries. Secondly, if in addition to the capital requirement policy instrument, a transfer of resources between national governments and banks such as a bank levy or subsidy, is introduced into the model, national governments can fully customise banking regulation to the risk accumulated in their banking systems, despite incomplete information about the health of their banking sectors. These results suggest that the elements of decentralised policy-making should be strengthened in the further development of the European banking union. Given the current debate and the emerging banking union in the eurozone, our paper offers a word of caution against pushing centralisation too far, using a rigorous theoretical analysis based on a well-known economic theorem.

Our paper presents a highly stylised model of banking regulation in the eurozone. Admittedly, the model abstracts from important issues related to the institutional set-up of the banking union, such as the inner working of the institutions involved in banking regulation and the cooperation of the institutions on the European level such as the ECB with the national authorities that will remain critical in day-to-day supervision. In a very comprehensive review of banking regulation and supervision in the emerging banking union in the eurozone, Tröger (2014) argues that the distribution of competences between the ECB and national authorities is too imbalanced for an optimal inter-agency cooperation to emerge and, hence raises doubts with regard to the effectiveness of the chosen set-up.

Another important aspect that is related to the institutional set-up of the banking union but lies outside the scope of our paper concerns the possibility of conflicts between the financial stability and monetary policy goals. Our model abstracts from the possibility of policy conflicts that may arise if, for example, securing financial stability calls for a more lenient monetary policy than is warranted by the inflation forecast. In the end, in particular if both policy functions are combined under the same roof without appropriate safeguards in place, policy credibility may be impaired and the effectiveness of policy interventions may suffer (e.g., Cecchetti and Li, 2008 and Ueda and Valencia, 2014). 


\section{Appendices}

\section{Appendix 1: Model set-up}

\section{Federal Policymaker}

(FP)

\section{Country 1}

Banks are privately informed of the true state of their balance sheets

\section{Country 2}

Banks' balance sheets are ex-ante healthy

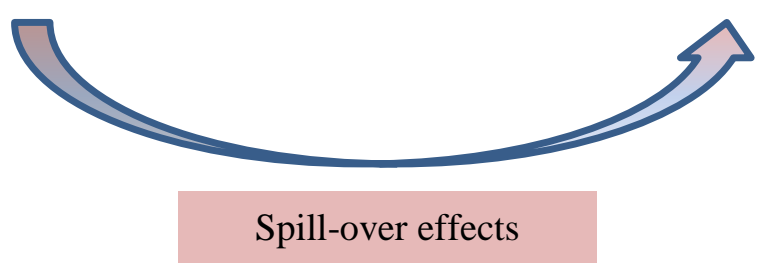

\section{Appendix 2: Derivation of $w^{j}$}

Substituting out $\tau_{1}^{j}, c_{1}{ }^{j}$, and $c_{2}{ }^{j}$ from (2) and (7) using (3a), (3b), and (11) yields:

$$
\begin{aligned}
w^{j}= & \frac{1}{2}\left[m_{1}+u\left(q_{1}^{j}\right)-\frac{\delta^{j} \cdot\left(q_{1}^{j}\right)^{2}}{2}-D\left(\eta \delta^{j} q_{1}^{j}\right)\right] \\
& +\frac{1}{2}\left[m_{2}+u\left(q_{2}\right)-\frac{\delta^{L} \cdot\left(q_{2}\right)^{2}}{2}-D\left((1-\eta) \delta^{j} q_{1}^{j}+\delta^{L} q_{2}\right)\right]
\end{aligned}
$$

for $j=H$ or $L$. Substituting (12a) and (12b) into the above equation and applying Proposition 1 yields: 


$$
\begin{aligned}
& w^{j}\left(r_{1}, r_{2}\right)=\frac{1}{2}\left[m_{1}+u\left(\frac{p_{1}-r_{1}}{\delta^{j}}\right)-\frac{\delta^{j} \cdot\left(\frac{p_{1}-r_{1}}{\delta^{j}}\right)^{2}}{2}-D\left(\eta \delta^{j} \frac{p_{1}-r_{1}}{\delta^{j}}\right)\right] \\
& \frac{1}{2}\left[m_{2}+u\left(\frac{p_{2}-r_{2}}{\delta^{L}}\right)-\frac{\delta^{L} \cdot\left(\frac{p_{2}-r_{2}}{\delta^{L}}\right)^{2}}{2}-D\left((1-\eta) \delta^{j} \frac{p_{1}-r_{1}}{\delta^{j}}+\delta^{L} \frac{p_{2}-r_{2}}{\delta^{L}}\right)\right],
\end{aligned}
$$

for $j=H$ or $L$.

\section{Appendix 3: IC constraints}

(15c) and (15d) imply

$$
\frac{\left(p_{1}-r_{1}^{H}\right)^{2}}{2 \delta^{H}}-\frac{\left(p_{1}-r_{1}^{L}\right)^{2}}{2 \delta^{H}} \geq x_{1}^{L}-x_{1}^{H} \geq \frac{\left(p_{1}-r_{1}^{H}\right)^{2}}{2 \delta^{L}}-\frac{\left(p_{1}-r_{1}^{L}\right)^{2}}{2 \delta^{L}}
$$

Therefore,

$$
\frac{\left(p_{1}-r_{1}^{H}\right)^{2}-\left(p_{1}-r_{1}^{L}\right)^{2}}{2 \delta^{H}} \geq \frac{\left(p_{1}-r_{1}^{H}\right)^{2}-\left(p_{1}-r_{1}^{L}\right)^{2}}{2 \delta^{L}}
$$

Applying $\delta^{L}<\delta^{H}$ yields Proposition 1.

\section{Appendix 4: Derivation of $w^{j}$ with bank levies}

Substituting out $\tau_{1}^{j}, c_{1}^{j}$, and $c_{1}{ }^{j}$ from (2a) and (7a) using (3a), (3b) and (11) yields:

$$
\begin{aligned}
w^{j}= & \frac{1}{2}\left[m_{1}+u\left(q_{1}^{j}\right)-\frac{\delta^{j} \cdot\left(q_{1}^{j}\right)^{2}}{2}-D\left(\eta \delta^{j} q_{1}^{j}\right)-x_{1}^{j}\right] \\
& +\frac{1}{2}\left[m_{2}+u\left(q_{2}\right)-\frac{\delta^{L} \cdot\left(q_{2}\right)^{2}}{2}-D\left((1-\eta) \delta^{j} q_{1}^{j}+\delta^{L} q_{2}\right)-x_{2}\right]_{; j=H, L .} .
\end{aligned}
$$


Substituting (12a) and (12b) into the above equation yields:

$$
\begin{aligned}
& \left.w^{j}\left(r_{1}\right)\left[\begin{array}{l}
\frac{1}{2} \\
x_{1}^{j}, r_{2} \\
m_{1}+u\left(\frac{\left.x_{2}\right)}{p_{1}-\bar{r}_{1}^{j}}\right. \\
\delta^{j}
\end{array}\right)-\frac{\delta^{j} \cdot\left(\frac{p_{1}-r_{1}^{j}}{\delta^{j}}\right)^{2}}{2}-D\left(\eta \delta^{j} \frac{p_{1}-r_{1}^{j}}{\delta^{j}}\right)-x_{1}^{j}\right] \\
& \frac{1}{2}\left[m_{2}+u\left(\frac{p_{2}-r_{2}}{\delta^{L}}\right)-\frac{\delta^{L} \cdot\left(\frac{p_{2}-r_{2}}{\delta^{L}}\right)^{2}}{2}-D\left((1-\eta) \delta^{j} \frac{p_{1}-r_{1}^{j}}{\delta^{j}}+\delta^{L} \frac{p_{2}-r_{2}}{\delta^{L}}\right)-x_{2}\right]
\end{aligned}
$$

$j=H$ or $L$.

\section{Appendix 5: Solving for the first-best allocation}

Stages 3 and 2 remain the same as before. The first-best allocation corresponds to the case without information asymmetry in stage 1 (hence no IC or IR constraints). The CA's objective function simply is $V=U\left(w_{1}^{j}\right)+U\left(w_{2}^{j}\right)$, where

$$
\begin{aligned}
w_{I}^{j}= & m_{1}+u\left(q_{1}^{j}\right)-\frac{\delta^{j} \cdot\left(q_{1}^{j}\right)^{2}}{2}-D\left(c_{1}^{j}\right) \\
= & m_{1}+u\left(\frac{p_{1}-r_{1}^{j}}{\delta^{j}}\right)-\frac{\delta^{j} \cdot\left(\frac{p_{1}-r_{1}^{j}}{\delta^{j}}\right)^{2}}{2}-D\left(\eta \delta^{j} \frac{p_{1}-r_{1}^{j}}{\delta^{j}}\right)
\end{aligned}
$$

where $j$ is either $H$ or $L$ (and it is known). In this case, there is no $x$ in the welfare function because it cancels out between the payer (government) and recipients (banks). As the banks' decision on $q$ is independent of $x$, and by assumption profits are positive $(p>r)$, there is no need for $x$ anyway.

Likewise, 


$$
\begin{aligned}
w 2^{j}= & m_{2}+u\left(q_{2}\right)-\frac{\delta^{L} \cdot\left(q_{2}\right)^{2}}{2}-D\left(c_{2}^{j}\right) \\
= & m_{2}+u\left(\frac{p_{2}-r_{2}}{\delta^{L}}\right)-\frac{\delta^{L} \cdot\left(\frac{p_{2}-r_{2}}{\delta^{L}}\right)^{2}}{2}-D\left((1-\eta) \delta^{j} \frac{p_{1}-r_{1}^{j}}{\delta^{j}}+\delta^{L} \frac{p_{2}-r_{2}}{\delta^{L}}\right) .
\end{aligned}
$$

The FOCs with respect to $r_{I}^{j}$ and $r_{2}$ are now given by

$$
\begin{aligned}
& u^{\prime}\left(q_{1}^{j}\right)=p_{1}-r_{1}^{j}+\eta \delta^{j} D^{\prime}\left(c_{1}^{j}\right)+(1-\eta) \delta^{j} D^{\prime}\left(c_{2}^{j}\right) \\
& u^{\prime}\left(q_{2}\right)=p_{2}-r_{2}+\delta^{L} D^{\prime}\left(c_{2}^{j}\right)
\end{aligned}
$$

(Note that $U^{\prime}\left(w_{1}^{j}\right)=U^{\prime}\left(w_{2}^{j}\right) \equiv U^{\prime}(w)$ in stage 3 (see (10)), hence they cancel out.) To verify whether Proposition $1^{\prime}$ can be consistent with the first-best, totally differentiate $\left(21 \mathrm{a}^{*}\right)$ and $\left(21 b^{*}\right)$, and we have

$$
\begin{aligned}
& {\left[-\frac{u^{\prime \prime}\left(q_{1}^{j}\right)}{\delta^{j}}+1+\eta^{2} \delta^{j} D^{\prime \prime}\left(c_{1}^{j}\right)+(1-\eta)^{2} \delta^{j} D^{\prime \prime}\left(c_{2}^{j}\right)\right] d r_{1}^{j}=-\frac{u^{\prime \prime}\left(q_{1}^{j}\right) r_{1}^{j}}{\left(\delta^{j}\right)^{2}} d \delta^{j}} \\
& (1-\eta) \delta^{L} D^{\prime \prime}\left(c_{2}^{j}\right) d r_{1}^{j}+\left[-\frac{u^{\prime \prime}\left(q_{2}\right)}{\delta^{L}}+1+\delta^{L} D^{\prime \prime}\left(c_{2}^{j}\right)\right] d r_{2}=0
\end{aligned}
$$

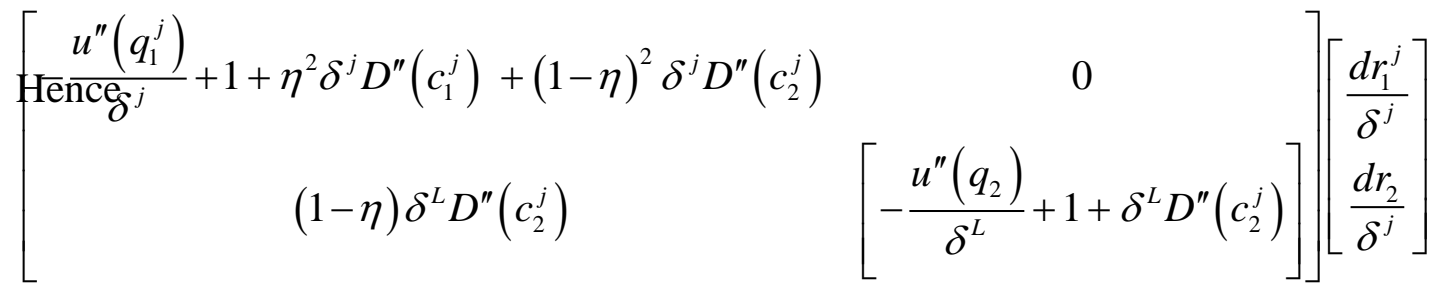

$$
\begin{aligned}
& =\left[\begin{array}{c}
-\frac{u^{\prime \prime}\left(q_{1}^{j}\right) r_{1}^{j}}{\left(\delta^{j}\right)^{2}} \\
0
\end{array}\right]
\end{aligned}
$$

Let $\boldsymbol{J}$ denote the Jacobian coefficient matrix of $\left(23^{*}\right)$. Then using the Cramer's rule 
$\frac{d r_{1}^{j}}{\delta^{j}}=\frac{1}{|\boldsymbol{J}|}\left|\begin{array}{cc}-\frac{u^{\prime \prime}\left(q_{1}^{j}\right) r_{1}^{j}}{\left(\delta^{j}\right)^{2}} & 0 \\ 0 & {\left[-\frac{u^{\prime \prime}\left(q_{2}\right)}{\delta^{L}}+1+\delta^{L} D^{\prime \prime}\left(c_{2}^{j}\right)\right.}\end{array}\right|>0$.

Therefore, $r_{l}^{H}>r_{l}^{L}$ at the optimum. Hence Corollary 1 of the constrained optimum is consistent with the first-best. 


\section{References}

Acharya, V. (2003). Is the International Convergence of Capital Adequacy Regulation Desirable?, Journal of Finance 58, 2745 - 2781.

Allen, F., T. Beck, E. Carletti, P. Lane, D. Schoenmaker and W. Wagner (2011). CrossBorder Banking in Europe: Implications for Financial Stability and Macroeconomic Policies, CEPR Report, London.

Beck, T., R. Todorov and W. Wagner (2013). Supervising Cross-border Banks: Theory, Evidence and Policy, Economic Policy 28, 5 - 44.

Becker, G. (1981). A Treatise on the Family, Harvard Univ. Press, Cambridge, MA.

Bergstrom, C. and T. Bergstrom (1999). Does Mother Nature Punish Rotten Kids?, Journal of Bioeconomics $1,47-72$.

Calzolari, G. and G. Loranth (2011). Regulation of Multinational Banks: A Theoretical Inquiry, Journal of Financial Intermediation 20, 178-198.

Caplan, A., R Cornes and E. Silva (2000). Pure Public Goods and Income Redistribution in a Federation with Decentralized Leadership and Imperfect Labor Mobility, Journal of Public Economics 77, 265 - 284.

Cecchetti, S. and L. Li (2008). Do Capital Adequacy Requirements Matter For Monetary Policy?, Economic Inquiry 46, 643-659

Chami, R. and C. Fullenkamp (2002). Trust and Efficiency, Journal of Banking \& Finance $26,1785-180.9$

Dell'Ariccia, G. and R. Marquez (2006). Competition Among Regulators and Credit Market Integration, Journal of Financial Economics 79, 401-430.

Goyal, R., P. Koeva Brooks, M. Pradhan, T. Tressel, G. Dell'Ariccia, R. Leckow and C. Pazarbasioglu (2013). A Banking Union for the Euro Area, IMF Discussion Note 13/01, Washington, DC.

Holthausen, C. and T. Ronde (2004). Cooperation in International Banking Supervision, ECB Working Paper 316, European Central Bank, Frankfurt. 
IMF (2010). A Fair and Substantial Contribution by the Financial Sector, Final Report for the G20, Washington, DC.

Jürges, H. (2000), Of Rotten Kids and Rawlsian Parents: The Optimal Timing of Intergenerational Transfers, Journal of Population Economics 13, 147 - 157.

Keen, M. (2011). Rethinking the Taxation of the Financial Sector, CESifo Economic Studies $57,1-24$.

Lee, C., M. Hsieh and H. Dai (2012). How Does Foreign Bank Ownership in the Banking Sector Affect Domestic Bank Behaviour? A Dynamic Panel Data Analysis, Bulletin of Economic Research 64, Supplement Issue, 86 - 108.

Morrison, A. and L. White (2009). Level Playing Fields in International Financial Regulation, Journal of Finance 64, 1099 - 1142.

Nagase, Y. and E. Silva (2000). Optimal Control of Acid Rain in a Federation with Decentralized Leadership and Information, Journal of Environmental Economics and Management 40, 164 - 180.

Pisani-Ferry, J., A. Sapir, N. Véron and G. Wolff et al. (2012). What Kind of European Banking Union?, Bruegel Policy Contribution 2012/12, Brussels.

Saha, B. and R. Sensarma (2011). Mixed Ownership, Managerial Incentives and Bank Competition, Bulletin of Economic Research 63, 385 - 403.

Schoenmaker, D. and S. Oosterloo (2005). Financial Supervision in an Integrating Europe: Measuring Cross-Border Externalities, International Finance 8, 1- 27.

Schoenmaker, D. (2011). The Financial Trilemma, Economics Letters 111, 57-59.

Schoenmaker, D. (2013). Governance of International Banking: The Financial Trilemma, Oxford University Press, Oxford.

Shambaugh, J. (2012). The Euro's Three Crises, Brookings Papers on Economic Activity, 1, $157-211$.

Sapir, A., M. Hellwig and M. Pagano (2012). A Contribution from the Chair and Vice-Chairs of the Advisory Scientific Committee for the Discussion on the European Commission's Banking Union Proposals, Advisory Scientific Committee to the European Systemic Risk 
Board, Frankfurt. Available: https://www.esrb.europa.eu/pub/asc/html/index.en.html [accessed 2016-10-25].

Silva, E. (2016). Decentralized Leadership, CESifo Working Paper No. 6064, Munich.

Schularick, M. and A. Taylor (2012). Credit Booms Gone Bust: Monetary Policy, Leverage Cycles, and Financial Crises, 1870-2008, American Economic Review 102, 1029 - 1061.

Taylor, A. (2012). The Great Leveraging, NBER Working Paper No. 18290, Cambridge, MA.

Tröger, T. (2014). The Single Supervisory Mechanism - Panacea or Quack Banking Regulation?, European Business Organization Law Review 15, 449 - 497.

Ueda, K. and F. Valencia (2014). Central Bank Independence and Macro-prudential Regulation, Economics Letters 125, 327-330.

Vives, X. (2001). Restructuring Financial Regulation in the European Monetary Union, Journal of Financial Services Research 19, 57 - 82. 